\title{
PROFESSIONALISM
}

ISSN: 1893-1049

Volume 9, No 1 (2019), e2862

http://doi.org/10.7577/pp.2862

Anette Lykke Hindhede \& Vibeke Andersen

\section{Interdisciplinary Promises and Hierarchical Ambiguities in a Danish Hospital Context}

\begin{abstract}
The public health sector in welfare states is increasingly subject to organisational changes, particularly in hospitals, as organisations comprise coalitions of various (healthcare) professionals. In this context, due to interprofessional competition, knowledge claims play an important role in achieving jurisdictional control. In this paper, we investigate the manifestations of and health professionals' reactions to competing institutional discourses. Through qualitative interviews with hospital management, middle managers, and staff employees at three hospitals in Denmark, we demonstrate how managerial attempts to control tenacious professional bureaucracies are exercised through both bureaucratic forms of control and cultural-ideological modes of control with an introduction of new discourses of interprofessional teamwork. The findings suggest that hospitals seek not only to contain ambiguity through bureaucratic features of control, but also to cultivate it when seeking to strengthen cooperation between professions. Thereby, ambiguity itself becomes a mechanism for management.
\end{abstract}

Keywords: Autonomy, control, ambiguity, interprofessional education, jurisdiction, professionalism, power, critical management studies, discourse, public hospitals

Anette Lykke

Hindhede,

Aalborg University,

Denmark

Vibeke Andersen, Aalborg University, Denmark

\section{Contact:}

Anette Lykke

Hindhede,

Aalborg University,

Denmark

alh@learning.aau.

$\underline{\mathrm{dk}}$
The public health sector is increasingly subject to organisational changes. Among these is the application of Lean manufacturing principles to public health sector activities that focus on cutting out waste whilst continuing to ensure quality, which has been rapidly diffusing into the sector with claims of "providing a much-needed rethink of traditional ways of working and stimulating performance improvements" (McCann, Hassard, Granter \& Hyde 2015, p. 1557). However, along with Lean, we see an emerging form of managerial practice which Kunda (1992, p. 11) defines as normative control and "the attempt to elicit and direct the required efforts of members by controlling the underlying experience, thoughts, and feelings that guide their actions". One such discourse that promises to separate power differences among employees and increase their awareness of each other's workplace contributions is Interprofessional Education. This discourse is touted in internationally acclaimed reports (WHO, 2010; Frenk et al., 2010) as the solution to future healthcare challenges such as diminishing resources, an ageing population and workforce, and advancements in medicine that enable people with complex healthcare problems to live longer, requiring more care. The ability to collaborate is thus increasingly considered
Received:

9 Aug 2018

Accepted: 17 Jan 2019 
a basic competency for healthcare professionals, and Inter Professional Education has become a core curricular component in many health professions' international education programmes where it is introduced as an effective evidence-based method for establishing continuity of patient care (Gittell, Godfrey, \& Thistlethwaite, 2013; Jørgensen, Jeppesen, \& Hotzman, 2010).

Inter Professional Education was developed in Canada. Behind the concept is the desire for a democratic professional practice based on the understanding that a pressing problem in healthcare is that health professionals cannot or will not cooperate (Axelsson \& Axelsson, 2009). D'Amour and Oandasan (2005) provide the following definition of interprofessional learning and cooperation: "interprofessionality is defined as the development of cohesive practice between professionals from different disciplines," and "interprofessionality requires a paradigm shift, since interprofessional practice has unique characteristics in terms of values, codes of conduct, and ways of working" (p. 9). The intention is therefore to address the power dynamics among healthcare professionals and equalise the statuses among them.

What is not clear in the literature on this topic in general, however, is precisely who collaborates with whom, or how exactly collaboration is defined. Moreover, this normative form of control of healthcare professionals is intended for public hospitals, which are generally bureaucratic organisations with many layers of hierarchical professional knowledge distribution and the formalisation and standardisation of work processes, and which are ultimately accountable to democratically elected politicians (Mintzberg, 1989). Hospital professionals are faced with the dilemma of developing standardised practices in order to reduce ambiguity (Baker \& Denis, 2011) while at the same being confronted with real human beings. They have historically resisted new ways of organising work that challenges their dominance and autonomy (Flynn, 1999; Freidson, 1994; Harrison \& Ahmad, 2000; Mintzberg, 1989). The focus on healthcare professionals as both objects of control and exercisers of control was coined by Friedman (1986, p. 121) when stating:

There is always a fundamental tension between the need to gain cooperation or consent from those who do the work, and the need to force them to do things they do not wish to do, or to be treated in a way which is against their own interests, in order that the goals of those "in control" of the labour process be achieved.

The inherent ambiguity in the hierarchical relations and managerial answers to this challenge is the focus of this paper. Rather than considering control in hierarchical relations as merely a matter of subjugation, in this paper control is analysed as a complex and ambiguous dynamic depending on (a sense of) employee autonomy to succeed.

In the study of professions, a classic twist is typically seen with regard to the question of whether knowledge or power is fundamental (Abbott, 1988, 2005; Brante, 2010; Evetts, 2003; Harrits, 2014; Saks, 2010). In this article, the methodological and analytical strategy is to study hospital professions at the point of overlap between power and knowledge within organisations that seem to have constructed a combination of bureaucratic and normative or cultural-ideological frameworks (Kärreman \& Alvesson, 2004, p. 151), thus potentially generating highly ambiguous norms about work. Our research question is as follows:

What are the manifestations of and reactions to competing institutional discourses in hospitals when healthcare professionals seeking to achieve jurisdictional control are faced with both bureaucratic and cultural-ideological forms of control at the same time?

\section{Theoretical background}

The managerial work of bringing these "tenacious" professional bureaucracies under 
more comprehensive control (Bode, Lange \& Märker, 2016, p.1) involves different types of standardisation, such as standardised work methodologies, division of labour, formal HRM procedures, etc. and to simultaneously offer the bureaucracies increased autonomy at work by introducing Interprofessional Education. In order to address these issues, we consider it fruitful to draw on critical management studies and their research into new forms of management in a context of organizational complexity (Alvesson \& Willmot 1992, 2003). Organisational complexity means that there is not necessarily any established form of consensus, consistency, or clarity in the culture of the organisation. The focus on ambiguity enables us to determine what is shared in the organisation, and what is not. According to Alvesson (1993), ambiguity is a condition that can be empirically developed by focusing on: 1) what counts as knowledge (about how the work is best organised and performed); 2) how managers and employees make sense of this knowledge; and 3) what the knowledge should produce. Alvesson's point is that this ambiguity leads to an interpretive space: "the ambiguity of knowledge and the work ... means that "knowledge", "expertise" and "solving problems" to a large degree become matters of beliefs, impressions and negotiations of meaning" (Alvesson, 2001, p. 870). Alvesson and Willmott (2002) argue that company leadership seeks to achieve organisational control in different ways "through the self-positioning of employees within managerially inspired discourses" (p. 620). However, according to the authors, this can never be fully achieved, since the meaning of such attempts is negotiated by employees with "other elements of life history forged by a capacity to accomplish life projects out of various sources of influence and inspiration" (Alvesson \& Willmott, 2002, p. 628). This suggests the importance of focusing on how people are continuously "engaged in forming, repairing, maintaining, strengthening or revising the constructions that are productive of a sense of coherence and distinctiveness" (Alvesson \& Sveningsson, 2003, p. 1165).

According to Abbott (1988), the authority in a profession's knowledge is dependent on achieving successful jurisdiction demands. This process is determined in a power struggle, where the number and quality of knowledge resources in the profession and its individual members is crucial. Thus, when the member of top management in the following sections speaks of the correct "culture" as the one that is defined by the doctor group, the relative value of the other professional groups in the hospital is made clear. From Alvesson's perspective, this means that hospital employees are steered through the management's indirect articulations of professional affiliations.

\section{Context and setting}

Since the beginning of the 2000s, many Lean initiatives, both large and small, have been carried out at Danish hospitals (Arlbjørn, Nørby, Norlyk, Wiborg \& Holm, 2008, p. 149), and many hospitals continue to work based on Lean principles.

Lean is a management philosophy and methodology that was developed in Toyota's factories in Japan in the 1960s, which revolutionized the manufacture of physical goods. In a healthcare context, mainstream prescriptive discourses suggest that Lean "provides a much-needed rethink of traditional ways of working and stimulating radical performance improvements" (McCann et al., 2015).

The Danish version of Interprofessional Education also aims to fundamentally change organisational thinking and values when stating that "interprofessional education can reduce the number of complications, admission time, conflicts between health professionals, number of admissions and mortality rates" (Jørgensen et al., 2010). The Danish players behind Interprofessional Education emphasize the initial evidence that it has a positive impact on clinical quality, patient safety, and patient satisfaction, as well as on employee satisfaction (Zwarenstein, Goldman \& Reeves, 2009). 


\section{Method and analysis strategy}

In order to identify potential competing institutional discourses, we conducted semistructured qualitative interviews with a total of 14 health professionals at 3 large Danish public hospitals: hospital A, with 12,000 employees; B, with 2,700 employees; and C, with 3,000 employees. The hospitals were chosen based on their explicit use of the new socio-ideological tool of Interprofessional Education. The respondents were selected opportunistically and were primarily middle managers thus they had considerable responsibility for managing people and processes. All were on or close to the front line of patient care, and were thus both managers and part of "the managed." They were able to provide rich information on how organizational changes had been translated into daily practice. All respondents had many years of experience in the hospital sector. They were assured anonymity prior to participating in the project. Therefore, in the analyses, we have given them fictional initials and removed the locations of the hospitals.

The interviews lasted approximately one hour each, were conducted by the two authors, and took place mainly in the hospital, though some were conducted via Skype. In one case, we interviewed two respondents simultaneously. All interviews were recorded and transcribed.

Drawing on the initial theoretical perspectives of critical management scholars alongside Abbott, as described above, we focused in the interviews on the discursive possibilities available across two professional groups, nurses and physicians, when they (re)construct their professional selves in relation to the management discourses introduced. These discursive possibilities are important elements in management since knowledge defines the knower: what one is able to do (or is expected to be able to do) frames who one "is" (Alvesson \& Wilmott, 2002). Therefore, we asked about each respondent's experience with the specific tools used, and how the respondent created meaning with these tools with regard to his or her own understanding of how professional work in healthcare is best carried out - by whom and why. We were not able to observe the practices. Instead, we drew on Nicolini's (2009) method to articulate and represent practice by "interviewing to the double," a technique that requires the respondents to imagine they have a double who will have to show up for their jobs the next day. The respondent is then asked to provide the necessary detailed instructions for the work to be done. These narratives are, according to Nicolini, often morally connoted and idealized in character. We systematically analysed the transcripts with a focus on what orients the conduct of health professionals and the normative and moral dimensions of practice in an era of Inter Professional Education: which inclusion and exclusion mechanisms were constructed? What was constructed as obvious versus surprising? How did this affect the legitimate modes of professionalism and action? By comparing these questions, a complex picture emerged of the ambiguous representations of management forms of control, making it possible to develop themes that fell broadly into three main categories: 1) normative forms of control; 2) achieving control by jurisdiction demands; and 3) the interplay between control forms. These themes form the subsections in the findings and highlight how ambiguity predominated as a central feature of the hospital culture.

\section{Findings}

\section{Normative forms of control}

All three hospitals have many years of experience with Lean as a method for standardizing workflows. As a lead doctor in a department at hospital B says, "Here, we put in a lot of effort to plan some programmes, guidelines, and procedures to get something to flow better. There are guidelines for almost everything; there is a long 
tradition for it." To "get something to flow better" can be interpreted as an attempt by management to reduce ambiguity, as "the practices of quantification, standardization and classification ... work to reduce ambiguities" (Best, 2012, p. 91). All the respondents, from all three hospitals, mentioned that they are regularly introduced to new management tools. One of our interviewees, Michael, is currently part of the top management at hospital A but also has top management experience from hospital B. We asked him how the management has decided to handle the different tools. Michael explained that they are careful not to implement new management tools blindly, but instead to consider what makes sense for the individual department.

Michael: The dangerous thing is to make a big campaign and say, "Now we are doing Inter Professional Education projects," and then afterwards we do Lean projects, and then suddenly there are "patient-responsible doctor" projects, and then suddenly, on top of everything, there are cutbacks, and then none of it matters. [We do it] in such a way, so that it's a tool we can cope with and handle, that our own consultants can use when they are out in situations in the hospital where it makes sense. Because there are some departments where Inter Professional Education is the answer... There are other departments where it's Lean that's needed. And in other departments it's sometimes a direct order that is needed; elsewhere, it can be education.

As indicated by the phrase "there are cut-backs," in Denmark, the hospital sector as a whole is highly politically managed and subject to regular demands for savings. Michael links Inter Professional Education, Lean, "responsible doctor," "direct orders," and "education," thus designating them as management tools that do not necessarily need to be implemented all over the hospital. Moreover, to him, such projects cannot be realized in times of cutbacks. They only gain footing in certain situations, and they need to "make sense." Notably, he sees "Inter Professional Education" as something other than "education." We therefore asked Michael what problem Inter Professional Education is supposed to solve.

Michael: Some of the departments where I think Inter Professional Education could be something you should consider are where there is a poor working environment, places where there is low patient satisfaction or places where you have to work across departments.

When Michael explains how Inter Professional Education can be fruitful in departments with poor working environments, this may reflect the WHO document, which positions Inter Professional Education as a vehicle for making trainees "collaborative practice ready" (WHO, 2010, p. 12) and suggests that poor working environments are due to the staff not collaborating enough. To Michael, Inter Professional Education can also help with low patient satisfaction or increase cross-department collaboration. He does not, however, indicate how Interprofessional Education does these things or whether it should be implemented at the undergraduate, postgraduate, or practice level, which creates the possibility for many different interpretations amongst the health professionals about what the primary purpose of it is, and how it should be implemented in practice. By not being explicit as to how exactly it creates collaborative practice-ready health professionals and happy patients, ambiguity is compounded rather than reduced. We, therefore, asked what he as part of the top management based his decision on when deciding to introduce Inter Professional Education in the departments.

Michael: I think it's very, very important that there is a genuine interest amongst all professional groups, not least amongst the doctors, to want this. If those doctors who set the tone don't have a genuine interest in this and really go for it, then you can really work with it, but you don't get the full effect out of it.... So, if there 
isn't a culture with a genuine interest and desire for this, then you can make schedules on the walls from here to Christmas; it doesn't change anything.... The places I've seen where it really flourished and has really done something, it's been in the passionate group, if you can say it like that, where there have been some leading doctors who have dragged the culture with them.

All professionals should be able to see an interest in strengthening cooperation, which signals attempts to control exercised through promises of autonomy. Not all professionals have an equal say in the matter, however, which generates ambiguous norms about work. According to Michael, it is ultimately the doctor group that decides whether the tool becomes a part of daily practice or not, since the doctor group "sets the tone." This corresponds to the experience of Marie, a staff nurse serving on the staff of Hospital A, when she provided insight into the top management's strategy for the introduction of tools:

Marie: The philosophy has been, "We cannot get everyone onboard." So, there are a few islands around the hospital where it's being used.... At these big hospitals, you make a lot out of testing the water, since there is a high level of autonomy.... It's a bit difficult to be one of the few.... If it seriously has to become a new culture, the physician management has to be involved.... You have to be careful not to present a framework that is too fixed, because already then, they get annoyed.... It's something like giving people free reign but at the same time controlling it slightly from above.

It is quite clear who holds decision-making power and how management relates to this, thus maintaining hierarchical differences. Thus, health professionals are confronted with both classic bureaucratic and normative involvement-based forms of control at once: "Do not present a framework that is too fixed' AND 'control it from above".

\section{Achieving control by jurisdiction demands}

As we initially described, contemporary bureaucracies are typically organised through routines and standardisations for exercising control and handling ambiguities. However, the above quotes show that such strategies do not always work in this context, where the doctor profession has, according to the top management, won the right to determine what the "correct" culture is considered to be. Abbott (1988) explains how full jurisdiction is based on professionals' complex knowledge, which gives them the power to define and solve particular issues. Professionals strive for complete, legitimate control of work and knowledge areas as well as the opportunity to defend and expand these areas. In this hospital context, there is also the issue of what Abbott calls subordination as jurisdiction, which is when a given professional area (in this case, the nursing profession) is subordinate to another (the doctor profession). This subordination requires a certain "symbolic order" that includes "the use of honorifics, the wearing of uniforms and other symbols of authority, and countless similar behaviors" (Abbott 1988, p. 72-73). Here, this interprofessional relationship is clarified by the nursing group working with tools that deal with cooperation and respect for each other's professional areas, while the dominant professions are not necessarily invested in engaging with them.

In hospital B, two years ago, the top management chose to introduce Interprofessional Education as a true top-down decision. In the implementation phase, each department could decide how they would work with the tools, as Martin, physician and department head, explained.

Martin: It was good that the hospital decided to work with Interprofessional Education because it meant that it was forced down in the organization and that's 
good.... Every department was instructed to work with things in a way that made sense to them.... First, we [the department's management] did something with interdisciplinary conversations and conferences. Because at that time you talked about patient involvement; it was a little in fashion. And then we decided to introduce the ward rounds involving patients.... We don't put it out there for discussion, because it's a concept that is developed, and if it doesn't work after three months, then we'll drop it again.

In this quote, we see that Martin has a broad definition of Interprofessional Education, including "interdisciplinary conversations," "patient involvement," "ward rounds," and "conferences." At the same time, he sees much of it as a fad, as in, "it was a little in fashion." Thus, Martin represents practice as a place with many changing discourses regarding what the right way to act as a health professional is. At the same time, however, it is important for Martin that the concepts introduced have been developed to be well received at the ward level. Later in our conversation with Martin, from highlighting the positive aspects of the top-down implementation of the tool, pivoted to emphasizing autonomy as crucial to his wellbeing.

Martin: I hate all that top-down management. My managers do not involve themselves in what we do. They trust us. And that's the kind of support you should have. So, if any problems arise, they have to give support. Because they shouldn't manage; they don't know what happens in practice.

Martin's representations of hospital practice help identify what slips out, does not fit, or gets lost in translation in top management's attempts to handle ambiguity (Best, 2012). The risk of using a top-down management strategy to avoid ambiguity in the organization, by giving specific and exhaustive instructions in the use of collaboration tools, is that such precision may lead to a lack of flexibility, which will annoy someone like Martin. On the other hand, a strategy with intentional ambiguitybased on letting the individual hospital department decide what they understand by interprofessional practice - enables a more flexible use of the tools and will please someone like Martin. In both cases, however, the ambiguity continues.

Alvesson points to the use of consultants as a strategy management uses to increase legitimacy when something new is to be introduced. As expressed in Martin's remark below, the health professionals have extensive experience with both internal and external consultants in their work of bringing these "tenacious" professional bureaucracies under more comprehensive control, as when exposing them to projects with new types of tools. However, for Martin, it does not seem that this increases legitimacy.

Martin: Most of them [projects with tools] are old wine in new bottles, and typically there's a 35-year-old consultant with high heels and clever expressions. Then you just get incredibly tired of it, because you know you have to go back and do a mountain of work.

Again, he emphasizes that these types of tools are superfluous rather than actually helping the hospital carry out work when under pressure. Another head of department, Patricia, from hospital A, expressed the same understanding.

Patricia: I can also have a tendency to think that it's a bit of hot air. But it is a little more systematic and allows the patients to be involved in some advice. And then something about how you design outpatient clinics... but really it doesn't affect my daily practice.... It was launched by the former centre director. Often, they have a strategy, and then they throw a few million [Danish kroner] at it. 
affect daily workflow. Martin expressed it thus: "It's not a given that interdisciplinary cooperation makes it better. [It only works] if rules are introduced about what it is you have to contribute. It's about us knowing what each other's subject areas are and that we don't cross them." He continued:

Martin: Including patients and relatives in every consideration requires a big professional identity.... But there is not so much professional identity amongst the nurses, even though they are actually the group that is around the patients the most.... You only become good with the interdisciplinary side if you are good in your own profession. Because otherwise, it will be a kind of porridge, where nobody is good anymore because everyone distances themselves from responsibility.

From the nurses' perspective, Interprofessional Education helps to increase the individual's professional identity, since it forces professionals to think about what their role is in the everyday work around the patient. Lisa, an expert nurse who serves on the staff at hospital B and is a trained facilitator, also explained that, in her experience, not all professionals see the point of interdisciplinary cooperation. Even though almost every single patient meets several professionals during their admission, Lisa believes that the worker's medical specialty is crucial to whether they experience the tool as relevant.

Lisa: My experience is that it doesn't seem important to talk to each other across specialties.... It is typically easier to sell it [the tool] within specialties, where there is a great need for interdisciplinary cooperation.

With this, Lisa indicates that it is not necessary to know what every other staff member does across all specialties. She points out that interdisciplinarity can be an ambiguous concept that is not clearly defined by management when they introduce tools for individual departments. This point was also reflected in our conversation with Hans, department head at hospital C, who explained that he had chosen to work on the patient-involving rounds in his department.

Interviewer: And you maintain professional competencies even though it's Interprofessional Education? And let the doctor lead the ward even though there may be a nurse who has been on a course about it?

Hans: We're not Interprofessional Education pioneers. We do it because it's a ward. It's the doctor who leads the meeting no matter what, and that shouldn't be changed. Each time you put something up for assessment in an organization, you're getting out a can of petrol and a match - and it happens every time - that it then has to be discussed. But this is not an interdisciplinary meeting. It is the doctor's meeting with the patient where we invite others (professional groups) because we think it is interdisciplinary.

Hans represents practice as a place where it is the doctor who is responsible for the ward, even though it is practised in new ways, where those in other professions are invited when necessary. To him, interdisciplinary cooperation is not about professional borders being diluted, but rather that mono-professionalism must be strengthened, thus reinforcing professional stereotypes and the hierarchy of professions (Hindhede \& Larsen, 2018). Morality and values are articulated by the profession that has jurisdiction: the doctor group. In Hans's understanding, the more monoprofessional the department's function, the better the interprofessional cooperation becomes. The ambiguity from management with regard to what Interprofessional Education is good for is an invitation for the employees to contribute to an interpretation exercise. In this way, the introduction of the tool is very efficient for purposes 
of management: by presenting it as something that individual employees can themselves interpret, management creates an opportunity for employees to arrive at the understanding that best fits their professional identity without a great deal of opposition. In this way, the doctor interprets Interprofessional Education as supporting the cementing of mono-professionalism as the best way to achieve good interprofessional work, and the nurse - who, according to the doctor group, does not have a strong professional identity - feels respected by the tool for his or her own area of responsibility, which is defined by the doctor profession.

\section{The interplay between control forms}

In all three hospitals, the version of leanness that is used is known as "performance goal management": a tool with a focus on regional performance goals, where data about the centre and clinic levels is found. Employees must follow up on these regional performance goals, but they are allowed to supplement the regional goals with their own goals that the local management perceives as relevant. "Whiteboard meetings" enable a department's staff to meet once a week in front of a whiteboard and discuss the goals the department has set for itself. These can concern anything, such as the continuity of care across clinics, the patient-involving ward, screening for bed sores, doctor-contact agreements, or wellbeing. An administering senior doctor at hospital C, Tom, described the morning meetings in the operating hall as being the situation where Interprofessional Education was practised. However, based on his explanation of the content, it is not clear how the professions were collaborating.

Tom: Twenty minutes can easily be spent in the operating hall for the morning meeting, and if we don't reach the last patient, then they are a costly twenty minutes; I've pointed this out several times. Many things can be talked about, but the important thing is the production and target numbers. We have to achieve 2,100 operations. Graphs are used, and "Where are we this month and where should we be?" The target numbers are incredibly important and they occur again and again. I have regular meetings where we talk about how we best fill the beds.... The challenge with something having to be measured constantly is that things are changing all the time. Often the goal is not the goal anymore. And those goals can easily restrict us. Some goals we can't reach, which is why we use delaying tactics, just to be able to say that now the goal has been achieved, for example, with the contact person arrangement. There must be a name, but you are not always a function but just a title.

The goals move and change, and rather than the employees being restricted by these standardizations, they choose to interpret them so that they fit into their daily practice. A tool such as Interprofessional Education is also billed as a way to measure work and to increase productivity. For this study, we asked the respondents for their perceptions of these measuring tools. It appeared that the doctor profession emphasized different elements than the nursing profession. First, we present some statements from the doctors. The top management member of hospital A, Michael, talked about the Interprofessional Education tool and its measurability.

Michael: I don't know anything about the model. And it's not about me having to understand everything in detail in order to believe it, but I'm sceptical about it. It has to be much more solid and tested elsewhere before I think we need to spend time on making before and after measurements on a large scale.

Thus, Michael does not experience the performance indicators as transparent. $\mathrm{He}$ questions the tool's measurement criteria. When we asked Mona, a chief surgeon from hospital B, if they use the measurable parts of Interprofessional Education in her department, she explained: 
Mona: The Interprofessional Education COMPASS tool can measure, but we don't use it. We don't have time, so a luxury like being able to measure things, unless it's hardcore data, we don't have time for it. We are working flat out and can't do the everyday things.... But when we did patient-involving rounds, we measured it. With before and after measurements. Otherwise, you can't know whether it works.

Here, measurability is not questioned in the same way. Mona indicates that she is able to code the ambiguity convincingly by turning some of the work of measuring into a luxury. Thus, a distinction is drawn between the measurement of hardcore data and the type of data that the tools generate. As the day-to-day manager of the department, she helps define what is important to measure and what is less important, which matches the regional policy that, for both department and hospital, measurements must be made on some parameters, while other parameters are voluntary. Here, Mona indicates that there is no reason to measure something for which the department is not required to provide an accounting. Thus, she makes use of a specific vocabulary of motives with her staff group regarding what is and what is not important in their work.

Common to the doctor profession and represented by the statements above is the notion that there are right and wrong ways to measure and that there must be evidence for something to be recognized as useful. At the same time, a distinction is drawn between those measurements involving hard data and more uncertain qualitative and ambiguous measurement methods. The doctor group has jurisdiction to interpret what is the "right" knowledge about how to best measure a given output. As can be seen, the polyvalence of the ambiguous measurement methods is difficult to control and can give rise to creative misunderstandings that reduce control for those who have decided that performance goal management should be introduced.

More nuanced representations of practice and how the work is best organized and performed were expressed amongst those in the nursing profession. Here, bureaucratic forms of control such as measurability was not seen as a criterion for the tool to be useful. Instead, the focus was on the process. We interviewed a lead nurse, Anna, who is part of the overall interdisciplinary management team in a department at hospital C, regarding her attitude towards Interprofessional Education. She explained that her interest was in how to plan the organization of work in hospital departments so that they function as well as possible: "I am busy with the staff seeing each other's competencies. That takes some time. Over time, my need to know why I do what I do has increased - and to get some theory about it. So, that's why I took the facilitator education." An instance of how she saw others' competencies was the morning meetings in the operating hall, the same place Tom had described. Anna explained further when asked about the importance of measurability for Interprofessional Education.

Anna: No... the project was hugely successful, and everyone felt that it had been a lot of fun and a lot of new things happened, but we scored low. So, we've discovered that it is more important to be in the process and not necessarily to have a goal.... It was because the surgeons were tired of the project. They thought that it had been a disturbance, so they scored it low. But the nurses scored it high; they thought it was great.

Interviewer: Then what did you do about it?

Anna: Well, we can see that they work well together.

Interviewer: Can Interprofessional Education increase productivity?

Anna: Yes, it does, absolutely. Because everyone is much more aware of each other's roles and you are quicker getting started. And it increases the quality of what they are doing. In relation to safe surgery, we actually score the highest in the country, and that is after we have run Interprofessional Education. But just 
the exercise of working with some performance goals, then especially the doctors react by saying, "Yes, but what do other studies say?" etcetera.

According to Anna, a sign of a successful interprofessional practice is that "everyone is much more aware of each other's roles" and that "you are quicker getting started." She expresses norms of "working well together," although it is not quite clear how this is done.

\section{Conclusion and discussion}

In this article, we have investigated the ambiguities involved in organizational cultures of three Danish public hospitals. They are dominated by a logic of technical rationality and the accompanying efforts to standardize, quantify, and formalize as much of daily hospital practice as possible. This is displayed in a continuing introduction of management tools such as leanness, and more recently, Interprofessional Education as a new discourse and form of control. This combination of tools and concepts is deemed critical to the optimal functioning of healthcare systems as it is believed to improve efficiency, patient safety, and patient satisfaction, as well as to reduce healthcare costs and generally lead to improved health outcomes.

The condition of ambiguity in the hospitals was constructed by focusing on both what counts as knowledge about how the work is best organized and performed along with how managers at various levels of the organizations make sense of this knowledge. Finally, we have focused on the various representations of to what this knowledge should produce. Rather than operating with predefined normative positions, such as the victimised employees and more powerful managers, we asked about both the costs and the benefits of ambiguity for both managers and employees.

We found that the groups of doctors and nurses are both committed to interprofessional practice as a fruitful way of organizing work, although in one of the three hospitals, it was implemented as a top-down order. The respondents also agreed that Interprofessional Education was accepted due to being a "developed concept." Finally, in both groups, there were normative understandings of this tool as improving patient-centredness. However, although Interprofessional Education claims to be measurable, neither doctors nor nurses had positive experiences with that part of the tool; thus, in times of performance management, this was not translated into a positive attribute of the tool. Reflecting the findings of Carpenter and Dickinson (2011), in our study, professional stereotypes were in fact reinforced through Interprofessional Education activities, as both nurses and doctors emphasized that the strengthening of mono-professionalism was the goal of their collaborative practice, which thus affected how they translated the concept to practice. For nurses, though, the focus on mono-professionalism was considered helpful, as the tool led to them being recognized as a group of people whose voices are heard in interprofessional teamwork.

Our analyses also show how a gap occurs between the social production of knowledge about interdisciplinary cooperation in terms of measurable tools and the social experience of interprofessionality and cooperation around the patient amongst the different professional groups in the hospitals. This gap creates an interpretive space for both understanding and action. We found an interplay between three forms of control: 1) a technocratic form of control circling around the use of bureaucracy and performance measures (Kärreman \& Alvesson, 2004, p. 171); 2) with an element of jurisdiction control where it is the doctor profession that has the power to define the "right" knowledge and thus decide whether a tool that measures more ambiguous things such as wellbeing and collaboration will be implemented; and 3) a layer of socio-ideological control that addresses norms of values of collaboration and attempts to eliminate power, hierarchies, conflict, and their manifold consequences. 
Although we used the "interview to the double" technique to get normative representations of practice, we still have little information about what Interprofessional Education looks like and in what ways it is used. In the description of wards where workers from different professions are invited to go along with the doctor on rounds, it was not clear who did what. Another example was the morning meetings in the operating hall, which were represented as Interprofessional Education in practice no direct indications were provided of who collaborated with whom. We found that seeking to democratize how tools such as Interprofessional Education can be implemented can encourage more ambiguous management, in spite of political pressure to standardize and measure practice and outputs. In our study, democratizing the tools led to their being mobilized in ambiguous ways, to the extent that the notion of collaborative practice was rendered somewhat meaningless. Ambiguity thus had the social role of increasing the complexity of the management practices of the hospitals.

As many other scholars have mentioned (e.g., Kroezen et al., 2013), there exists a long sociological tradition of considering the effects of existing professional hierarchies, suggesting that professionals use demarcating strategies that divide rather than connect, and that institutional and organizational structures limit the ease with which collaborative practices can be implemented. One can pose the critique that with Interprofessional Education, education is considered the "solution" to problems that are in fact structural, organizational, and institutional matters. The history of health professionals delivering care together indicates that they hold different levels of legitimacy and thus differential scientific authority to define and lead best practices. Thus, enabling contact among them has not solved the problem of providing collaborative care.

A number of researchers have pointed out that there are particular difficulties associated with measuring the results of often broad political and social goals and formulating relevant indicators for these (Lee, Rainey \& Chun., 2009; Orr \& Vince, 2009; Pratchett \& Wingfield, 1996). Some of the arguments are that much of the work that is carried out in the public sector, in comparison to the private sector, is characterized by being less visible, less intentional, and more contradictory, which, according to Noordegraaf and Amba (2003), is due to changing political agendas and disagreement about which knowledge is the "right" kind, as well as unclear goal-method relationships. Typically, a paradox occurs because the handling of the problems is subject to an ambiguity that gives rise to an interpretative space. In this interpretative space, strict series of measurements do not work, since the set conditions and prerequisites cannot be fulfilled. Therefore, it does not make sense to measure, for example, interprofessionality.

The fact that ambiguity persists and even thrives in this kind of organizational context indicates that we must avoid overly simplistic assumptions about bureaucracy and that we must acknowledge the less rational side of these institutions (Best, 2012; Davies \& McGoey, 2012). The persistence of ambiguity - and its potential role as a kind of interpretative lubricant in an uncertain world - suggests that we should direct more attention to shifts and holes in these meaning-forming processes. Ambiguity invites us to consider what is lost in translation and to discover what other possibilities are getting away in these moments of miscommunication and reinterpretation (Best, 2012). At the same time, if ambiguities are not only impossible to eliminate but can actually be a source of authority through the power to interpret and define the "right knowledge," we can no longer expect bureaucracies such as public hospitals to be pure ambiguity-reducing machines. Instead, it would not be surprising to find a more managerially ambivalent attitude towards institutional ambiguity, as Best (2012) found at the IMF and the World Bank, and which it would also be unsurprising to find in hospitals, ministries, companies, and universities. In this way, ambiguity becomes a useful, but unpredictable, strategic tool in institutional struggles. 


\section{References}

Abbott, A. (1988). The system of professions: An essay on the division of expert labor. Chicago: University of Chicago Press. https://doi.org/10.7208/chicago/9780226189666.001.0001

Abbott, A. (2005). Linked ecologies: States and universities as environments for professions. Sociological Theory, 23(3), 245-274. https://doi.org/10.1111/j.0735-2751.2005.00253.x

Albert, M., \& Paradis, E. (2014). Social Scientists and Humanists in the Health Research Field. In D. Lee Kleinman, \& K. Moore (Eds). Routledge Handbook of Science, Technology, and Society (pp. 391-409). London: Routledge. https://doi.org/10.1111/j.1467-6486.1993.tb00476.x

Alvesson, M. (1993). Organizations as rhetoric: Knowledge - intensive firms and the struggle with ambiguity. Journal of Management studies, 30(6), 997-1015.

Alvesson, M. (2000). Social identity and the problem of loyalty in knowledgeintensive companies. Journal of Management Studies, 37(8), 1101-1123. https://doi.org/10.1111/j.1467-6486.1993.tb00476.x

Alvesson, M. (2001). Knowledge work: Ambiguity, image and identity. Human Relations, 54(7), 863-886. https://doi.org/10.1111/1467-6486.00218

Alvesson, M., \& Sveningsson, S. (2003). Good visions, bad micro-management and ugly ambiguity: Contradictions of (non-)leadership in a knowledgeintensive organization. Organization Studies, 24(6), 961-988. https://doi.org/10.1177/0018726701547004

Alvesson, M., \& Sveningsson, S. (2011). Identity work in consultancy projects: Ambiguity and distribution of credit and blame. In C. N. Candlin \& J. Chrichton (Eds.), Discourses of deficit (pp. 159-174). London: Palgrave Macmillan. https://doi.org/10.1177/0170840603024006007

Alvesson, M. and Willmott, H. (Eds) (1992). Critical Management Studies. London: Sage Publications Ltd. https://doi.org/10.1057/9780230299023 9

Alvesson, M. and Willmott, H. (Eds) (2003). Studying Management Critically. London: Sage Publications Ltd

Alvesson, M., \& Willmott, H. (2002). Identity regulation as organizational control: Producing the appropriate individual. Journal of Management Studies, 39(5), 619-644. https://doi.org/10.1111/1467-6486.00305

Arlbjørn, J. S., Nørby, M., Norlyk, B., Wiborg, K., \& Holm, N. (2008). Lean uden granser? [Lean without borders]. Aarhus: Academica.

Axelsson, S. B., \& Axelsson, R. (2009). From territoriality to altruism in interprofessional collaboration and leadership. Journal of Interprofessional Care, 23(4), 320-330. https://doi.org/10.1080/13561820902921811

Baker, G. R., \& Denis, J. L. (2011). Medical leadership in health care systems: from professional authority to organizational leadership. Public Money \& Management, 31(5), 355-362. https://doi.org/10.1080/09540962.2011.598349

Best, J. (2012) Bureaucratic ambiguity. Economy and Society, 41(1), 84-106. https://doi.org/10.1080/03085147.2011.637333

Bode, I., Lange, J., \& Märker, M. (2016) Caught in organized ambivalence: Institutional complexity and its implications in the German hospital sector. Public Management Review, 19(4), 1-17.

Brante, T. (2010) Professional fields and truth regimes: In search of alternative approaches. Comparative Sociology, 9(6), 843-886. https://doi.org/10.1163/156913310X522615

Carpenter, J., \& Dickinson, C. (2011). Contact is not enough: A social psychological perspective on interprofessional education. In S. Kitto, J. 
Chesters, J. Thristlewaite, \& S. Reeves (Eds.), Sociology of interprofessional health care practice: Critical reflections and concrete solutions (pp. 55-68). New York: Nova Science Publishers.

D'Amour, D., \& Oandasan, I. (2005) Interprofessionality as the field of interprofessional practice and interprofessional education: An emerging concept. Journal of Interprofessional Care, 19 (S1), 8-20. https://doi.org/10.1080/13561820500081604

Davies, W., \& McGoey, L. (2012). Rationalities of ignorance: On financial crisis and the ambivalence of neo-liberal epistemology. Economy and Society, 41(1), 64-83. https://doi.org/10.1080/03085147.2011.637331

Evetts, J. (2003). The sociological analysis of professionalism. International Sociology, 18(2), 395-415. https://doi.org/10.1177/0268580903018002005

Flynn, R. (1999) Managerialism, professionalism and quasi-markets. In M. Exworthy \& S. Halford (Eds.), Professionals and the new managerialism in the public sector (pp. 18-36). Buckingham: Open University Press.

Freidson, E. (1994). Professionalism reborn: Theory, prophecy, and policy. Chicago: University of Chicago Press.

Frenk, J., Chen, L., Bhutta, Z. A., Cohen, J., Crisp, N., Evans, T., \& Kistnasamy, B. (2010). Health professionals for a new century: transforming education to strengthen health systems in an interdependent world. The Lancet, 376(9756), 1923-1958. https://doi.org/10.1016/S0140-6736(10)61854-5

Friedman, A. (1986). Developing the managerial strategies approach to the labour process. Capital and Class, 10(3), 97-124. https://doi.org/10.1177/030981688603000107

Gittell, J. H., Godfrey, M., \& Thistlethwaite, J. (2013) Interprofessional collaborative practice and relational coordination: Improving healthcare through relationships. Journal of Interprofessional Care, 27(3), 210-213. https://doi.org/10.3109/13561820.2012.730564

Harrison, S., \& Ahmad, W. I. (2000). Medical autonomy and the UK state 1975 to 2025. Sociology, 34(1), 129-146. https://doi.org/10.1177/S0038038500000092

Harrits, G. S. (2014). Professional closure beyond state authorization. Professions and Professionalism, 4(1), 567. https://doi.org/10.7577/pp.567

Hindhede, A. L., \& Larsen, K. (2018). Prestige hierarchies of diseases and specialities in a field perspective. Social Theory \& Health, 1-18. https://doi.org/10.1057/s41285-018-0074-5

Jørgensen, P., Jeppesen, D., \& Holtzmann, J. (2010) Samarbejde på tvaers giver bedre resultat [Cross-cooperation gives better results]. March 19th, Politiken

Kroezen, M., van Dijk, L., Groenewegen, P. P., \& Francke, A. L. (2013). Knowledge claims, jurisdictional control and professional status: the case of nurse prescribing. PLoS One, 8(10), e77279. https://doi.org/10.1371/journal.pone.0077279

Kunda, G. (1992). Engineering Culture. Control and Commitment in a High-Tech Corporation. Philadelphia, PA: Temple University Press.

Kuper, A. \& Whitehead, C.R. (2012). The paradox of interprofessional education: IPE as a mechanism of maintaining physician power? Journal of Interprofessional Care, 26(5), 347-349. https://doi.org/10.3109/13561820.2012.689382

Kärreman, D., \& Alvesson, M. (2004). Cages in tandem: Management control, social identity, and identification in a knowledge-intensive firm. Organization, 11(1), 149-175. https://doi.org/10.1177/1350508404039662

Lee, J. W., Rainey, H. G., \& Chun, Y. H. (2009). Of politics and purpose: Political salience and goal ambiguity of US federal agencies. Public Administration, 
87(3), 457-484. https://doi.org/10.1111/j.1467-9299.2009.01772.x

McCann, L., Hassard, J. S., Granter, E., \& Hyde, P. J. (2015). Casting the lean spell: The promotion, dilution and erosion of lean management in the NHS. Human Relations, 68(10), 1557-1577. https://doi.org/10.1177/0018726714561697

Mintzberg, H. (1989). Mintzberg on management: Inside our strange world of organizations. New York: The Free Press.

Nicolini, D. (2009) Articulating practice through the interview to the double. Management Learning, 40(2), 195-212. https://doi.org/10.1177/1350507608101230

Noordegraaf, M., \& Abma, T. (2003) Management by measurement? Public management practices amidst ambiguity. Public Administration, 81(4), 853871. https://doi.org/10.1111/j.0033-3298.2003.00374.x

Orr, K., \& Vince, R. (2009) Traditions of local government. Public Administration, 87(3), 655-677. https://doi.org/10.1111/j.1467-9299.2009.01770.x

Paradis, E., \& Whitehead, C. R. (2015). Louder than words: power and conflict in interprofessional education articles, 1954-2013. Medical Education, 49(4), 399-407. https://doi.org/10.1111/medu.12668

Pratchett, L., \& Wingfield, M. (1996) Petty bureaucracy and woollyminded liberalism? The changing ethos of local government officers. Public Administration, 74(4), 639-656. https://doi.org/10.1111/j.14679299.1996.tb00888.x

Saks, M. (2010) Analyzing the professions: The case for the neo-Weberian approach. Comparative Sociology, 9(6), 887-915. https://doi.org/10.1163/156913310X522624

World Health Organization (WHO) (2010). Framework for action on interprofessional education and collaborative practice. Geneva: WHO.

Zwarenstein, M., Goldman, J., \& Reeves, S. (2009) Interprofessional collaboration: Effects of practice-based interventions on professional practice and healthcare outcomes. The Cochrane Database of Systematic Reviews, 8(3), CD000072. https://doi.org/10.1002/14651858.CD000072.pub2 